\title{
Centralized and decentralized control: Finding the right combination
}

\author{
H. de Haas, J. O. Riis, H-H Hvolby \\ Aalborg University, Department of Production, \\ Fibigerstraede 16, DK-9220 Aalborg, Denmark, \\ Tel: +4596358080, Fax: +4598153030, \\ E-mail:i9hhh@iprod.auc.dk
}

\begin{abstract}
The purpose of this paper is to introduce a more differentiated discussion of choosing an appropriate combination of centralized and decentralized planning and control. Based on identification of three main production control tasks, respectively focusing on customer orders, materials and capacity, we shall introduce a model to illustrate different decentralization strategies. The model has been used in industrial companies and stimulated constructive discussions.

To provide a better background for determining an appropriate control strategy we shall introduce a model with four interacting perspectives, representing major contextual elements . A case example is introduced and used to illustrate the use of the two models. Although by far not exhaustive, it is concluded that the two models have led to a more differentiated discussion of the important issue of finding an suitable combination of centralized and decentralized production control.
\end{abstract}

Key words

Centralized and decentralized tendencies, Models for control, Case study.

\section{INTRODUCTION}

In the beginning of 1992 a Danish company introduced a new product and experienced an explosive growth in sales and production volume which caused the traditional growth problems, e.g. lack of quality, failing deliveries etc. It was a daily fight for production to meet promised due dates. Management realized that it 
was necessary to change the traditional way of managing the company. Following, the company went through a change from a centralized hierarchical structure to a more decentralized structure where the employees were more involved in the daily management. The change was based on a Danish Kaizen program (MAPU Employee Activated Production Development), (DI 1993). Through this change the company introduced a number of production groups based on the identified production tasks. The measurable result of this process was a $12 \%$ increase in productivity in the first year after the change.

The case is not unique. As a result of a survey of six order producing companies (Haas and Hvolby, 1995) it was found that changes in the case companies clearly was a reaction to a number of tendencies in the industrial environment. When asked about their market conditions, all companies replied that the market had become increasingly turbulent and require customized products and short delivery times. This tendency imposes a need for more flexible and prompt reactions to changes. On the other hand, looking into the companies, the technological development during the past decade has made manufacturing processes more reliable. At the same time, the development in information technology has made it possible to collect and exchange almost every desirable type of information. Combined with the focus on suppliers prompt and accurate delivery, production control has actually become more deterministic, but increasingly complex.

Despite this change to a more deterministic internal environment, companies are still struggling with the traditional problems of centralized and decentralized production control, i.e. lack of coordination, missing information etc. As an example, the case company mentioned earlier found themselves in the situation where the central planning department believed that they were in charge of planning and control. In reality the foreman in each of the production areas was carrying out the planning and controlling of the production. It resulted in a suboptimization of production areas, e.g. high level of work in progress, failing deliveries etc.

As indicated above, the tendencies in production planning and control point in different directions with respect to centralization and decentralization. This calls for a more differentiated discussion than often seen in the literature (Mintzberg 1989). It is not a question of either centralized or decentralized control; rather a question of finding the right combination. Any mode of control in production holds elements of both centralized and decentralized measures, and the key issue is to seek an appropriate combination of the two.

We lack models which may support such a differentiated discussion. In this paper we shall introduce two models; the first one aims at illustrating different strategies for decentralization of production control. The second model will provide a contextual setting for evaluating and deciding on a strategy taking the specific characteristics of an individual industrial enterprise into account. A case example will be introduced and demonstrate how the two models may be used. In this way, the paper signifies a step towards a more differentiated view of the decentralization issue. 


\section{MODELS OF DECENTRALIZED CONTROL STRATEGIES}

We shall introduce a model which may illustrate the control structure of one central production control unit and three decentral production units, e.g. production groups. It rests on the assumption that the control of materials, capacity and customer orders are the main elements of any control effort. By indicating where the control of each factor is located, it is possible to depict a spectrum of different control structures. The letters $\mathrm{O}, \mathrm{M}$ and $\mathrm{C}$, respectively stand for the control of Customer Orders, Materials and Capacity, respectively. A letter in a box signifies that the pertinent task only sets the frame of control for a lower level.

In the following we shall describe three different examples of the model.

The first model for manufacturing control (figure 1) is the traditional hierarchical model where the main decisions are made at the central level, e.g. decisions on material requirements and purchase, capacity planning and order control. This type of control appears suitable for a company in an environment with high determinism and with well defined production control tasks at each level of control.

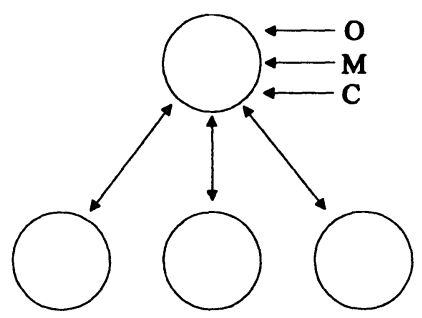

Figure 1 A highly centralized way of control

The second model (figure 2) places the production control task of capacity control at the decentralized level based on a capacity frame decided at the central control level. The order and materials control is still handled at the central level. An example of this model is a Danish shipyard which has divided production into production areas, i.e. self-controlling groups regarding the capacity control. The central level handles the long term, overall capacity control and the materials and order control. This type of production is characterized by large projects with by a large number of components joint together into one large product. The number of parts involved makes the material control very complex suggesting that the control task should be placed at the central level of control. At the same time, many production groups or departments will be involved in the manufacturing of the product which suggests that the order control should be placed at the central level as well. 


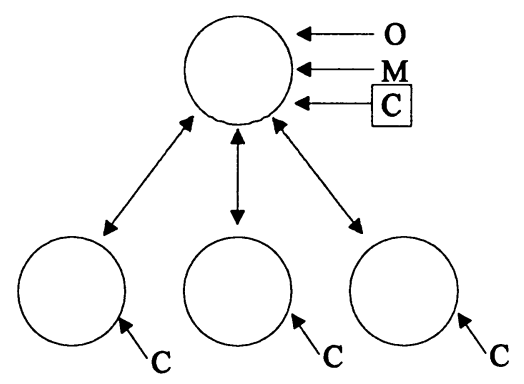

Figure 2 Decentralizing capacity control into each production area.

The third model (figure 3) shows a type of manufacturing where the central level onlyconcentrates on the overall control, i.e. setting frames for the control at the local level. This model can be found in companies manufacturing standard products. The type of product for this type of control may consist of a (relatively) small number of parts which reduces the complexity. The control approach will also be suitable for Kanban and Just In Time production.

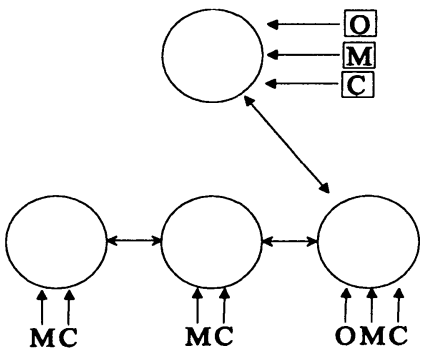

Figure 3 A highly decentralized model of control where central control is focused on long term decisions, while setting the frames of decentralized control.

Other examples may be illustrated by means of the model, for example a fully decentralized control with only minor control tasks at the central level.

The rather simple model has been used for depicting the current control structure in a number of industrial enterprises, and it has served as a basis for a useful discussion of the present situation as well as for identifying alternative control structures, reflecting both external and internal trends. The advantage of the model, is its simplicity which has made it possible to discuss different control strategies. Its limitation, of course, is the lack of details and its general nature. Hence, it is necessary to keep the specific situation of an enterprise in mind in the discussion as well as discuss the issue at a more detailed level, before a control structure may be decided upon in an enterprise. 
To provide a better background, we shall propose that four perspectives be taken into consideration when describing the context in which the issue of combining centralized and decentralized control measures is embedded.

\section{FOUR CONTEXTUAL PERSPECTIVES}

The model to be presented in this section aims to provide a basis for determining an appropriate combination of centralized and decentralized production control specific for an industrial enterprise. To represent major contextual parameters we have identified four perspectives, each of which describes an important part of the entire manufacturing process, cf. figure 4 .

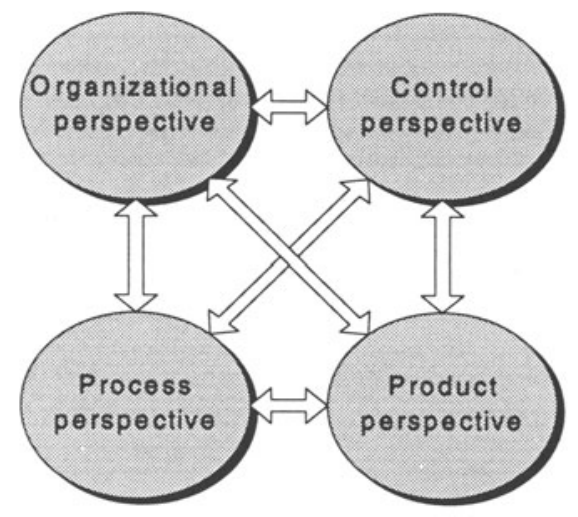

Figure 4: Contextual perspectives for determining an appropriate combination of centralized and decentralized production control.

The four perspectives all influence the production and the way of control. As an example, it is important to have knowledge of the mix of standard and customer specific products. The production of standard products can be planned with a shorter horizon and used as an equalizer for capacity demand. Production of customer specific products implies large variations in capacity demand and requires a flexible production. When looking at the four perspectives it is important to notice that one perspective is influencing the other. This means for example that the product perspective should be considered when looking at the process and control perspective. To illustrate, when a case company introduced a welding robot in the production they forgot to check whether the product would be suitable for the automated process equipment, and whether the control systems were prepared for this type of technology, and finally whether the employees needed further education. This is just one example of the introduction of new 
technology. Other examples will show that the same picture may be seen by introduction of new products.

\subsection{Control perspective}

The control perspective includes several complex elements. To be able to analyze the control perspective, a number of elements must be identified, e.g. control concept and control technology. The control perspective is defined as the task of controlling the process of transforming raw material into finished products. The control concept describes the placement of the push/pull line, the number of stocks, the processes and the layout of the production. Other aspects to be analyzed are the logistics complexity, e.g. if material flow is simple or complex, and the number of suppliers. Further, the control system used. For example MRP or Kanban are two different approaches, and they are suitable for different types of production.

\subsection{Organisational perspective}

Aspects like organisational roles, responsibility and the informal organization are ways to classify the organisational matters. Some aspects to consider are the number of levels in the production control, the degree of central or decentral control and thus the question of responsibilities vs. competence. This leads to the decision processes and the question of how simple or complex the structure need to be (clear decision hierarchy). Other questions in connection with organisational matters are the will to change, e.g. management, motivation. This is related to the culture of the company.

\subsection{Product perspective}

The product perspective influences the control by the way the products are built, e.g. the number of parts in the product, the degree of standardization. To determine the need of control, factors like standard or customer specific products (make to order or make to stock production) must be taken into consideration. This is regarded as a key point in the classification of a company control system. Another aspect to consider is the number of variants. The distinction between a standard product and a customer specific variant can be a key factor when determining the type of control. Another area is the complexity of the product. This is found by investigating the number of parts in the product and the levels in the Bill-OffMaterial (BOM).

\subsection{Process perspective}

Craft Production and Continuous Flow Manufacturing are two different aspects indicating the flexibility and complexity of production, e.g. high flexibility to changes and low volume of products in the direction of One-of-a-Kind production are typical for craft production. Processes in connection with craft production are most often less automatized and the capacity control is based on the work force. 
The continuous flow environment is characterized by low flexibility to changes and high volume production. The processes are most often placed in a line layout. Further it is relevant to investigate whether the production is automated or manual. The age of the manufacturing technology is attached to the above type of processes, e.g. welding robots are seen as a new technology in some companies whereas automatic conveyors are advanced in other companies. Further, it is important to bear in mind the link between the age of the technology and the type of process.

The following case shows how the model in figure 4 may be used. First we shall present an analysis of the current situation, then we shall identify areas for development, and finally propose a new concept for the control in the case company.

\section{DESIGNING DECENTRAL CONTROL - A CASE EXAMPLE}

The case company has 70 employees and is part of an international business group. Today, production planning is carried out by a central planner who has been in the company for more than 30 years and is soon to retire. He plans production by means of a master production plan and ends up with scheduling all machines. The production management has a vision of a self running production with a high degree of decentralized production control.

\subsection{External conditions}

Looking at the external conditions from an organizational point of view the company has difficulties in getting sufficient skilled workers. Regarding manufacturing processes, low cost countries in eastern Europe are now able to buy and manage advanced manufacturing equipment for use in the same processes. This means increased competition. Regarding the customers, the tendency is towards smaller batches with standard components customized to each customer order. Therefore the company must be more flexible and able to produce finished products closer to demand than before.

\subsection{The four perspectives and the company}

The model with the four perspectives, see figure 4 , is used for analyzing the company with the purpose of identifying the control tasks and their appropriate placement in the organization.

\subsubsection{Organizational perspective}

The organization is a typical functional organization with sales, finance and production departments, cf. figure 5. The company has conducted a number of different development projects including training courses, e.g. in group processes, conflict solving, psychological work environment and self control. 


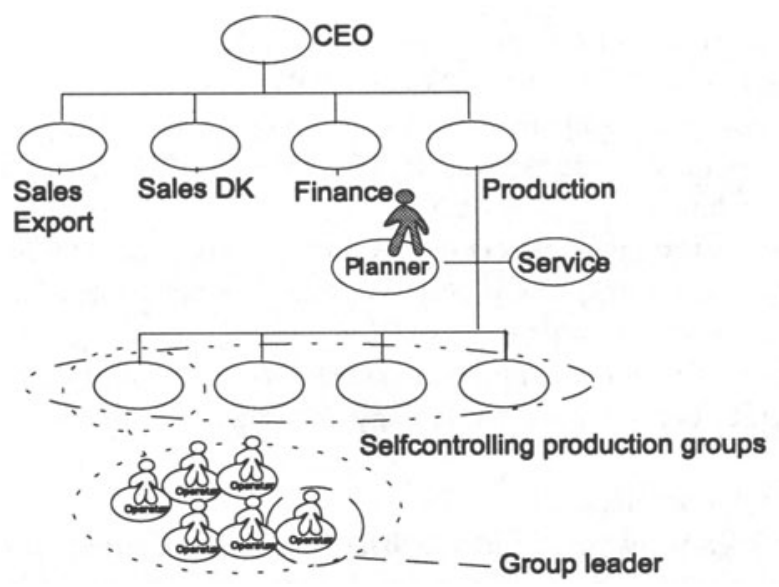

Figure 5: The formal organizational chart. The operators in production are organized in four self controlling groups

Some of the typical conflicts appearing in the company are mentioned here. As in every other company, the operators have different qualifications and preferences for processes. Some employees want a safe working environment, e.g. a locked schedule for production, a known machine. Others find it interesting to produce special orders under more uncertain circumstances e.g. high variety.

\subsubsection{Control perspective}

Production is partly order initiated and partly stock level initiated. The products are basically standard but can be customized. This gives a large variation of combinations. In practice the number of combinations is limited for example due to the construction of the current sales counters. Production layout is functional oriented. Figure 6 illustrates the control concept.

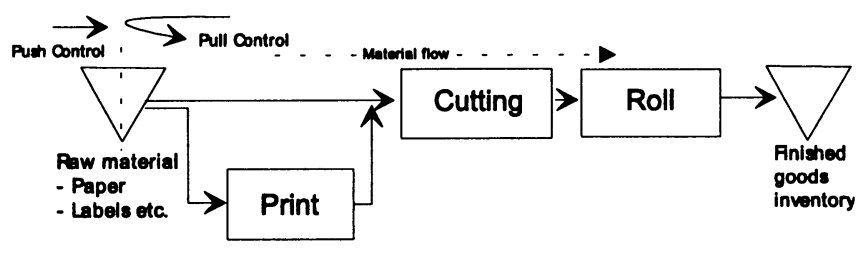

Figure 6: The present control concept showing the processes and the push and pull line.

The number of rolls is registered every day and statistics prepared so that each operator can see how much is produced and what the budgeted goal is. Operators have no possibility to see the connection between daily amount produced and the monthly overhead which is used for calculating the bonus, mainly because the 
variation over a week can be very large. The production control system is from IBM and of the type MOVEX, a traditional MRP system.

The production planning procedures are simple and tightly coupled to the MRP planning. When an order arrives, it is fed into the MRP system and scheduled for a specific machine.

Every morning a foreman collects the production orders for that day and distributes them to the operatores. The production manager makes a master plan with a horizon of 4 to 6 weeks, which is used for capacity planning, i.e. one to three shifts, etc. Furthermore a budget plan is made every year mainly for planning development activities in production technology and other investments.

\subsubsection{Product perspective}

The product is highly customer specific. The customer specific part of the product is for example the type of print on the roll or the length or width of the paper. These parameters give a large number of combinations for special products.

\subsubsection{Process perspective}

All products go through the same process chain which are typical for the branch. The processes are complex and demand some knowledge to operate. In general the operators have more knowledge about how to operate the machines than the production planner. The process flow is simple, i.e. one process is finishing a product except for the products that need printing. The process equipment in the production can be divided into two groups. The first group is characterized by having low set-up times and costs and medium speed. The other group is characterized by high production speed, high set-up times and costs. This division implies a division of the products into standard products with high volume, and special products with low volume.

\subsection{Summary of the four perspectives}

The company has been described based on the four perspectives, and it has been shown that the case company has a centralized control structure. In view of the three different control situations defined earlier, the company may be characterized as a type one shown in figure 1.

Looking through the perspectives for ways of improvement in this case company it was found that due to many small orders there are many set-ups in production, causing much set-up time and costs. The first suggestion would be to divide production into areas according to the different types of orders.

\subsection{The new concept}

It is proposed that the performance of the company may be improved through organizational and control routine changes towards a more decentralized production control structure. Development of a new structure for production control will be based on the four perspectives analysis which indicated a possibility 
of dividing the production into areas according to the sales volume of the different product types. The three areas found are showed in figure 7.

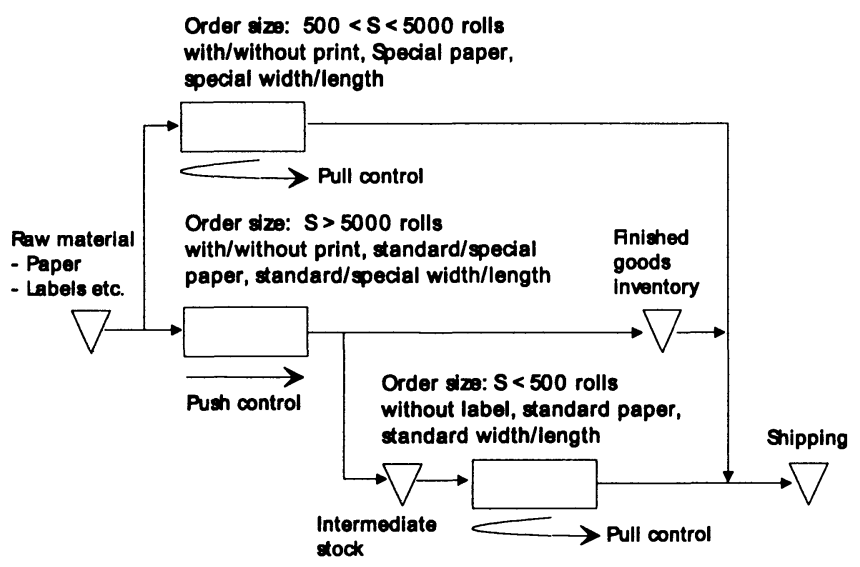

Figure 7: The new control concept with the division into production areas after order size and complexity.

In the new concept there will be one production area handling special orders with low volume and another area for high volume orders. The third area is for standard products in very low order batches and with a small degree of customization, but the packing is typically customer specific. The division follows the thoughts of focused factories by W.Skinner (1978). The organizational structure in the new system will be based on self-controlling production groups in some areas, and central control in other areas, i.e. a differentiated type of control based on the need for control in each area. As an example of the decentralization of control, the packing and shipping area, will be described in more details.

\subsubsection{The packing and shipping area}

According to the management, the packing and shipping area should have a very high degree of self-control, and will be a part of the existing finished goods stock. The principle of the system is that a few selected products are placed in large boxes waiting for the last process, i.e. packing and shipping. When a customer orders a product in a batch size that fits this area, the order goes directly to the area and into the line of orders to be packed and shipped. According to calculations these type of orders can be handled the same day giving a shorter delivery time to the customer.

The ordering of parts for the intermediate stock (cf. figure 7) and the packing area are to be as simple as possible, e.g. Kanban cards. The Kanban order can be rescheduled, if the load of customer orders is too high. To decentralize control the computer system will be distributed to the different production areas. Thereby the production groups are giving the possibility for updating order dates, e.g. comple- 
tion time, quantity etc. It is planned that the groups should collect their production orders from the system and also control the capacity.

\subsection{Case conclusion}

Inspired by the general discussion of how to combine the control levels by the three models in figure $1-3$, the case has illustrated the use of the four perspectives (cf. figure 4) as a frame for analyzing the case company. Through the interdependencies of the four perspectives some interesting questions were raised, and special focus was set on the interaction between the product perspective, control perspective and organizational perspective. Based on the findings a new way of control is described.

The change in the control structure may be described as a type three as shown in figure 3, a highly decentralized model for control. This is not absolutely correct because of the differentiation between the areas in the production. A better description would be a combination of the very decentralized approach and some centralized control.

\section{CONCLUSION}

This paper has aimed at stimulating a more differentiated discussion in industrial enterprises of choosing an appropriate combination of centralized and decentralized production planning and control. First, we introduced a rather simple model to capture the location of the control of respectively customer orders, materials and capacity, and to delineate the interaction between centralized and decentralized decisions.

Based on the case example in this paper and other empirical tests, we may conclude, that

centralized and decentralized control decisions are two sides of the same coin, and that it is important to focus attention on the interconnection between centralized and decentralized control decisions. A combination of centralized and decentralized control measures should be sought. Although simple, the model presented in this paper appears to be a useful vehicle for a stimulating discussion on these issues.

In the second model four perspectives were introduced to describe the context in which the issue of combining centralized and decentralized control measures is embedded. As discussed, the product and process perspectives influence the options available for selecting an appropriate combination, and it is our experience that often changes in the product program and in production processes are suggested during the decision making process. Similarly, the case example demonstrated that the two other perspectives introduced, the organizational and the control perspectives, are mutually interacting. We have observed that sometimes 
the organization has been changed, e.g. to production groups, but the control structure needs to be adjusted accordingly. And sometimes the opposite is the case.

Based on the case example and other empirical tests we may conclude, that

the four perspectives model may give rise to a fruitful dialogue between complementary factors influencing the choice of an appropriate combination of centralized and decentralized control. Furthermore, this discussion cannot be meaningfully carried out without the parallel consideration of respectively the control and the organizational perspective. This points to a need for means for demonstrating the mutual interaction of the two perspectives in practice, e.g. simulation games.

\section{REFERENCES}

Haas, Henning de and Hans-Henrik Hvolby, (1995): “A Holistic and Situational Approach for Effective Production Planning and Control" Molde College, Norway, May, 1995.

Skinner, W. (1978): “Manufacturing in the Corporate Strategy" Wiley, Chichester, UK

DI - Danish Industrial Society (1993): "Employee Activated Production Development" Danish Industrial Society, Denmark (in Danish).

Mintzberg, Henry (1989): "Mintzberg on Management: Inside our strange world of organizations" The Free Press, NY, USA.

\section{BIOGRAPHY}

Henning de Haas received his M.Sc. in engineering at the Department of Production, Aalborg University, in 1994 and completed his Ph.D. studies in the Summer of 1997. He is now employed at Bang \& Olufsen.

Jens O. Riis is a Professor of Industrial Management Systems at the Department of Production, Aalborg University, Denmark. He holds an M.Sc. in Mechanical Engineering from the Technical University of Denmark and a Ph.D. in Operations Research from the University of Pennsylvania, USA. His main teaching and research areas are design of production management systems, technology management, project management, and integrated production systems. Prof. Riis is a member of the IFIP Working Group 5.7 on Computer Aided Production Management Systems.

Hans-Henrik Hvolby is an Associate Professor focusing on production planning and control, order management and information systems. He received an M.Sc. in management systems from Aalborg University, Denmark in 1984, and in 1989 he earned a Ph.D. degree from the Department of Production, Aalborg University Since 1989 he has been on the faculty of the same department, interrupted by a two years leave of absence as a project manager with F.L. Smidt.. 